\title{
Modulation of Collagen Synthesis and Degradation by Retinoids and Cytokines in 3T3 L1 Preadipocytes
}

\author{
Satoshi Numaguchi, Masataka Okuno, Hisataka Moriwaki and Yasutoshi Muto
}

\begin{abstract}
We previously observed that a retinoid analog can protect against liver parenchymal damage and liver fibrosis, whereas it accelerates liver fibrosis which is not accompanied by any parenchymal damage. To elucidate these conflicting effects, we examined the effects of retinoid in $3 \mathrm{T3} \mathrm{L} 1$ preadipocytes as a model of liver stellate cells. Retinoids, including all-trans retinol, all-trans and 9-cis retinoic acids, enhanced the cell growth and the expression of the type I procollagen gene as well as its peptide synthesis, while reducing collagenase activities. Although no retinoid enhanced the transforming growth factor (TGF)-B1 mRNA, retinoids may stimulate collagen production through activating TGF- $B$, as was recently reported. These results help explain the observation in the liver fibrosis model with no parenchymal damage. In contrast, we also found that interferon (IFN) $\alpha \beta$ and $\gamma$ inhibited cell growth and down-regulated markedly type I procollagen as well as TGF-B1 mRNA, suggesting that they suppress by acting directly on extracellular matrix-producing cells.
\end{abstract}

(Internal Medicine 33: 309-316, 1994)

Key words: liver fibrosis, interferon, adipocytes, transforming growth factor- $\beta$

\section{Introduction}

Recent research on liver fibrosis has revealed that cytokines play important roles in activating stellate cells (fat-storing cells), thereby enhancing the production of extracellular matrix in the liver $(1,2)$. Several cytokines have been studied as candidates for such biological action, and transforming growth factor (TGF)- $\beta$ was found to be the strongest stimulant of extracellular matrix production (3-5). Also, efforts have been made to regulate the production of extracellular matrix and prevent or treat liver fibrosis $(1,2)$.

Interest has been focused on retinoids as one of the most promising group of agents for regulating liver fibrosis as retinoids disappear from stellate cells during the process of liver fibrosis (6). Previous studies have reported that retinoids inhibit the transformation of stellate cells into activated myofibroblastlike cells which have both an enhanced capacity to grow and to produce extracellular matrix (7). However, retinoids also seem to have conflicting actions in liver fibrosis. Recent molecular biology in retinoid research has revealed that the transcription of some extracellular matrix genes, such as laminin B1 and type IV procollagen, is activated through the binding of the nuclear receptor for retinoids to their responsive element in the pro- motor region of the extracellular matrix genes $(8,9)$. Moreover, an excess dose of vitamin A has also been reported to induce liver fibrosis in patients (10). We have reported previously that a retinoid analog inhibits liver parenchymal damage and liver fibrosis in a $\mathrm{CCl}_{4}$-induced liver cirrhosis model $(11,12)$. In another experiment, however, the retinoid analog showed no obvious inhibitory effect on liver fibrosis and rather seemed to stimulate the progress of liver fibrosis induced by intraperitoneal injections of porcine serum that was not associated with liver parenchymal damage (Okuno et al, unpublished observations).

In the present report, we describe our study of the effects of retinoids on the production and degradation of extracellular matrix by mesenchymal cells. This study was designed to help us better understand the role of retinoids in liver fibrosis. We employed 3T3 L1 preadipocytes as a model of liver stellate cells. Before differentiating into mature adipocytes, 3T3 L1 preadipocytes expressed high levels procollagens (types I, III and IV) and TGF- $\beta$ genes (13). The conversion of 3T3 L1 preadipocytes into adipocytes can be assumed to correspond to activated myofibroblast-like cells maturing to quiescent stellate cells. We also report in the present study the effect of interferons (IFNs) on the production of extracellular matrix.

From the First Department of Internal Medicine, Gifu University School of Medicine, Gifu

Received for publication September 6, 1993; Accepted for publication February 28, 1994

Reprint requests should be addressed to Dr. Yasutoshi Muto, the First Department of Internal Medicine, Gifu University School of Medicine, 40 Tsukasa-machi, Gifu 500 


\section{Materials and Methods}

\section{$3 T 3$ L1 cell culture}

3T3 L1 preadipocytes were a gift of the Japanese Cancer Research Resources Bank (Tokyo, Japan). More than $90 \%$ of the cells used in this study converted into mature adipocytes. Cells were normally grown in $25 \mathrm{~cm}^{2}$ flasks containing Dulbecco's modified Eagle's medium (D-MEM, GIBCO BRL, Inc., Tokyo, Japan) supplemented with $2 \mathrm{mM}$ glutamine and $10 \%$ fetal calf serum (GIBCO). Cells were fed $10 \mathrm{ml}$ of medium every 2-3 days during exponential growth and maintained in an atmosphere of $5 \% \mathrm{CO}_{2}$ and $95 \%$ air at $37^{\circ} \mathrm{C}$.

At confluence (approximately $2 \times 10^{6}$ cells per flask), preadipocytes were subjected to the differentiation protocol (14). The cells were exposed to $500 \mu \mathrm{M}$ of 1-methyl-3isobutylxanthine and $500 \mathrm{nM}$ of dexamethasone in the standard medium for $48 \mathrm{~h}$, followed by an additional 7 days of culture in the standard medium to induce the differentiation.

The stock solutions of all trans-retinol, all trans-retinoic acid, dexamethasone (Sigma Chemical Co., St. Louis, MO, U.S.A.) and 9 cis-retinoic acid (Eisai Co., Ltd., Tokyo, Japan) were $2 \mathrm{mM}$ in absolute ethanol. The stock solutions of TGF-B1 (Boehringer Mannheim Yamanouchi Co., Ltd., Tokyo, Japan) and mouse interferon (IFN) $\alpha \beta$ and $\gamma$ (Cosmo Bio Co., Ltd., Tokyo, Japan) were $100 \mathrm{ng} / \mathrm{ml}$ and $10^{5} \mathrm{U} / \mathrm{ml}$ in the standard medium, respectively. These stock solutions were diluted to the required concentration for use. Control cells were exposed to an equal volume of vehicle.

\section{Assay of cell growth}

Cell growth was assessed by the colorimetric tetrazolium (MTT) assay (15). Preadipocytes (approximately 3,000 cells/ well) were grown in the standard medium in the presence or absence of each agent in 96-well plates for 4 days, and 3-(4,5dimethylthiazol-2-yl) -2,5-diphenyl tetrazolium bromide was added to the cells according to the original method. The reaction was stopped by adding isopropanol- $\mathrm{HCl}$ after a $4 \mathrm{~h}$ incubation with tetrazolium and absorbance was measured using a microplate spectrophotometer.

\section{RNA extraction and northern blot hybridization analysis}

Total RNA was isolated from 3T3 L1 cells by the method of Chomczynski and Sacchi (16). Ten $\mu \mathrm{g}$ of total RNA was electrophoresed on a $1 \%$ agarose gel in the presence of formaldehyde and transferred to nylon membranes (Amersham Japan, Tokyo, Japan) by capillary action. The intensities of $28 \mathrm{~S}$ and $18 \mathrm{~S}$ ribosomal RNA bands were assessed by ethidium bromide staining. The membranes were then prehybridized at $65^{\circ} \mathrm{C}$ for $1 \mathrm{~h}$ in a buffer containing $6 \times \mathrm{SSC}(1 \times \mathrm{SSC}, 0.15 \mathrm{M}$ sodium chloride and $0.015 \mathrm{M}$ sodium citrate), $5 \times$ Denhardt's solution ( $1 \times$ solution, $0.02 \%$ polyvinylpyrolidone, $0.02 \%$ ficoll and $0.02 \%$ bovine serum albumin), $10 \%$ dextran sulfate and $1 \%$ sodium dodecyl sulfate (SDS) in the presence of $100 \mu \mathrm{g} / \mathrm{ml}$ denatured salmon testes DNA (Sigma), and hybridized at $65^{\circ} \mathrm{C}$ overnight in the above buffer with ${ }^{32} \mathrm{P}$-labeled probes $\left(2 \times 10^{6} \mathrm{cpm} / \mathrm{ml}\right)$ specific for human pro- $\alpha_{2}(\mathrm{I})$ collagen or human TGF- $\beta 1$. A
cDNA clone for pro- $\alpha_{2}(\mathrm{I})$ collagen was kindly provided by Dr. Mariko Seishima (Gifu University, Gifu, Japan) and a cDNA clone for TGF-B1 was kindly provided by Dr. Sumihare Noji (Tokushima University, Tokushima, Japan). The membranes were washed in $2 \times \mathrm{SSC}-0.5 \% \mathrm{SDS}$ for $10 \mathrm{~min}$ at room temperature, two times in $1 \times \mathrm{SSC}-1 \%$ SDS for $15 \mathrm{~min}$ at $65^{\circ} \mathrm{C}$, and finally in $0.1 \times \mathrm{SSC}-1 \% \mathrm{SDS}$ for $15 \mathrm{~min}$ at $65^{\circ} \mathrm{C}$. The hybridized blots were then exposed to XAR-2 films (Eastman Kodak Co., Rochester, NY, U.S.A.) at $-80^{\circ} \mathrm{C}$ using intensifying screens. Each band on the autoradiographs was quantitated using a flat head scanner (Epson Inc., Tokyo, Japan).

\section{Determination of collagenase activity}

Collagenase activities in the media were determined using the Collagenokit CLN-100 (Cosmo Bio). At confluency, 3T3 L1 preadipocytes were incubated with the retinoids, dexamethasone, TGF- $B 1$ or IFNs for $48 \mathrm{~h}$ in $3 \mathrm{ml}$ of standard medium using 6-well plates. The medium was centrifuged to remove cell debris and immediately subjected to the assay. The number and viability of the cells after the incubation were assessed by the MTT assay and proved to be equal in each well.

\section{Determination of collagen synthesis}

The rate of collagen synthesis was determined by an incorporation of ${ }^{14} \mathrm{C}$-proline into procollagen in confluent preadipocytes. For labelling, cells were incubated with $50 \mu \mathrm{Ci} /$ $\mathrm{ml}$ of $\mathrm{L}-\left[\mathrm{U}-{ }^{14} \mathrm{C}\right]$ proline (Amersham Japan) in fetal calf serumfree D-MEM for $10 \mathrm{~h}$ after pre-incubation with $100 \mu \mathrm{M}$ ascorbic acid (Sigma) and 500 $\mu$ M aminopropionitrile (Sigma) for 30 $\mathrm{min}$. Cell lysates were obtained by a sonication of cells in 50 $\mathrm{mM}$ Tris buffer at $\mathrm{pH} 7.4$ containing $0.5 \%$ Triton $\mathrm{X}-100$ and 10 $\mu \mathrm{g} / \mathrm{ml}$ type I collagen (Kikaku Collagen Gijutsu Kensyukai, Tokyo, Japan). Type I procollagen was separated using 5\% polyacrylamide gel electrophoresis in the presence of sodium dodecyl sulphate. Dried gels were exposed to XAR-2 films using intensifying screens. The synthesis rate of labelled procollagen was determined by the intensity of each band on the autoradiographs.

\section{Statistical analysis}

Comparison of group means was performed according to Dunnett's $t$-test.

\section{Results}

To explore the effects of retinoids on the extracellular matrix production in mesenchymal cells, we employed 3T3 L1 preadipocytes which have fibroblast-like morphology and form rosette-like shapes with triglyceride droplets surrounding their nucleus during differentiation (14). The differentiated mature adipocytes had markedly decreased their expression of type I procollagen and TGF- $\beta 1$ as previously described (13). Exposure of either 3T3 L1 preadipocytes or adipocytes to retinoids or cytokines did not alter the viability of the cells in the present experiment.

We first examined the regulation of extracellular matrix- 


\section{Retinoids Modulate Collagen Production}

producing cell growth by retinoids. Fig. 1 shows the effects of different concentrations of the retinoids on the growth of 3T3 L1 preadipocytes. All retinoids examined enhanced cell growth and all-trans retinol most strongly stimulated in a dose-dependent manner ( $285 \%$ of the control level at the concentration of 10 $\mu \mathrm{M})$. Both all-trans retinoic acid and 9-cis retinoic acid were relatively weak stimulants $(180 \%$ and $150 \%$ of the control levels, respectively, at $10 \mu \mathrm{M})$. We also examined the effect of glucocorticoid and cytokines as shown in Fig. 1. Dexamethasone showed no significant effect on cell growth. TGF-ß1, IFN $\alpha \beta$ and IFN $\gamma$ down-regulated cell growth in a dose-dependent manner (73\% of the control level for $10 \mathrm{ng} / \mathrm{ml}$ of TGF- 31 , and $52 \%$ and $60 \%$ for $400 \mathrm{U} / \mathrm{ml}$ of IFN $\alpha ß$ and IFN $\gamma$, respectively). No apparent cytotoxic affect was observed morphologically with treatment by either cytokine.

Since cell growth and expressions of extracellular matrix proteins and TGF- $\beta 1$ genes are known to be affected by the differentiation state of the adipocytes (13), we next examined the effect of retinoids on the differentiation of 3T3 L1 preadipocytes. Two different experiments were performed: one to study the long-term effect and the other to study the shortterm effect. The long-term incubation of preadipocytes with retinoids during the 7 day-differentiation protocol revealed that no obvious inhibition of differentiation by either retinoid (retinol or either isoform of retinoic acid) was observed on the morphology of mature 3T3 L1 adipocytes. Fig. 2 shows the short-term effects on the morphology of mature 3T3 L1 adipocytes. In the present experiment, retinoids were given for
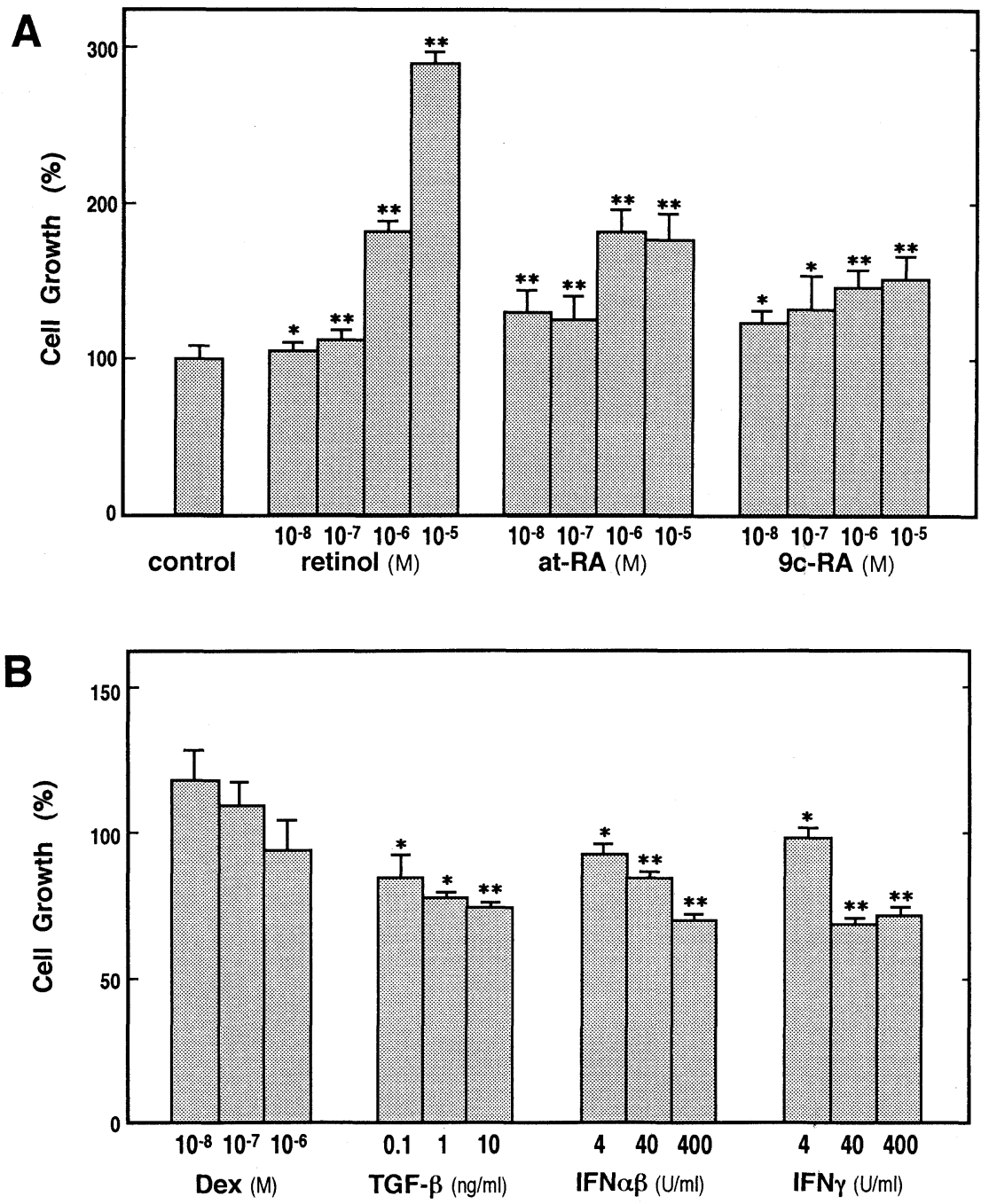

Fig. 1. Dose dependent effects of retinoids (Panel A) and cytokines (Panel B) on the cell growth of 3T3 L1 preadipocytes. The cells were exposed for $96 \mathrm{~h}$ to the indicated concentrations of the agents. The medium was changed every $24 \mathrm{~h}$ during the experiment and the cell growth was assessed by MTT assay as described in "Materials and Methods". Data are expressed as the percentage of control cell growth (treated only with vehicle). Values for each treatment represent the mean $\pm \mathrm{SD}(\mathrm{n}=6)$. Retinol: all-trans retinol, at RA: all-trans retinoic acid, 9c-RA: 9-cis retinoic acid, Dex: dexamethasone, TGF- $\beta$ : transforming growth factor- $\beta$, IFN: interferon. $*: \mathrm{P}<0.01, * *$ : $\mathrm{P}<0.001$. 


\section{NumAGUCHI et al}
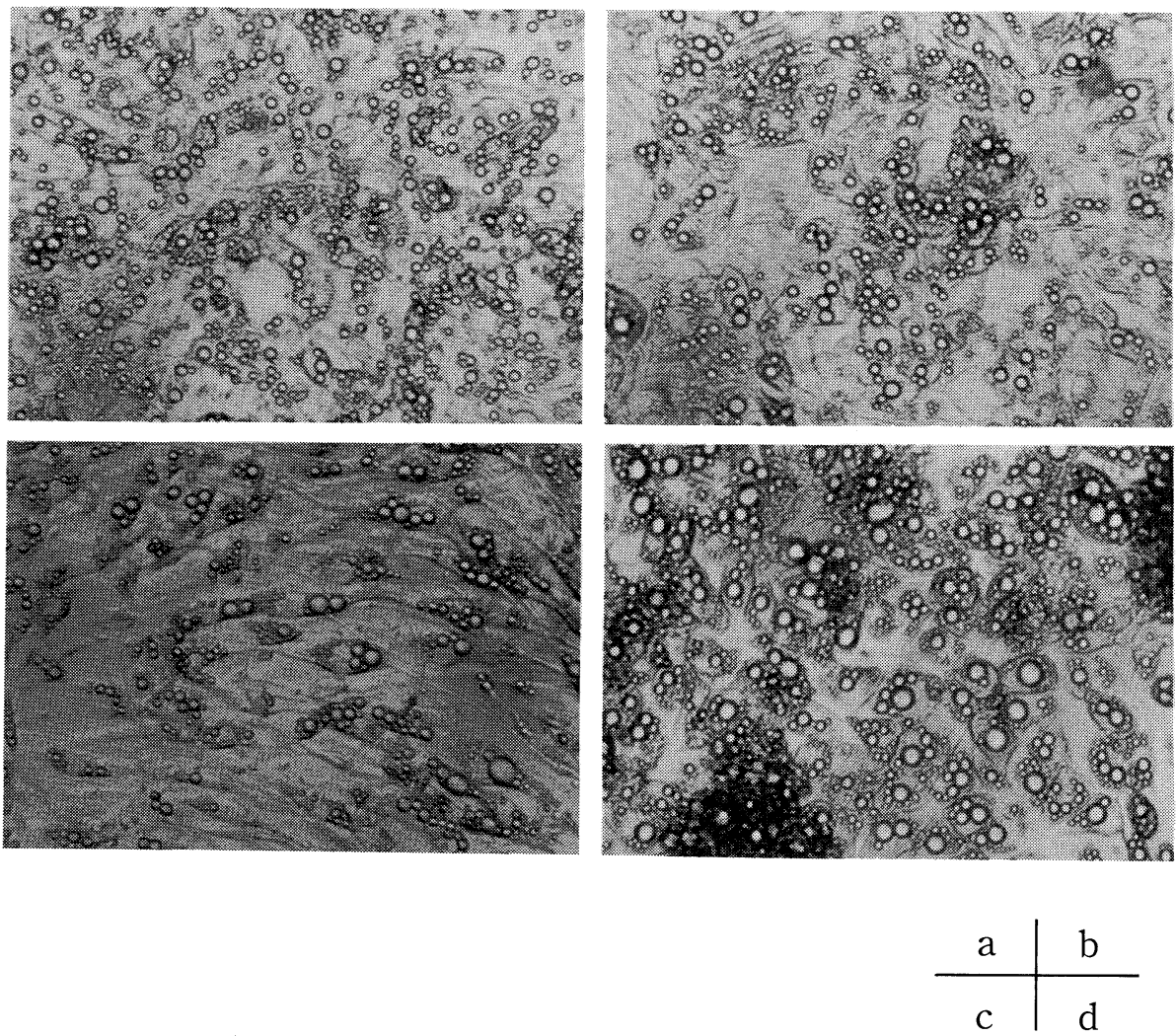

Fig. 2. Morphological alterations of mature $3 \mathrm{~T} 3 \mathrm{~L} 1$ adipocytes after a $48 \mathrm{~h}$ incubation with vehicle alone (a), $1 \mu \mathrm{M}$ of all-trans retinoic acid (at-RA) (b), $10 \mathrm{ng} / \mathrm{ml}$ of TGF-B1 (c) or $400 \mathrm{U} / \mathrm{ml}$ of IFN $\alpha \beta$ (d). The adipocytes were cultured for 9 days prior to this experiment to induce full differentiation according to the protocol as described in "Materials and Methods". Photographs show the representative features of the cells that were observed reproducibly in three independent experiments.

$48 \mathrm{~h}$ to the fully differentiated adipocytes which had been cultured for 7 days according to the standard differentiation protocol; no apparent morphological change was either observed by treatment with either retinoid (retinol or either isoform of retinoic acid). In contrast, TGF-B1 reduced significantly the number of differentiated adipocytes at the terminal stage of differentiation by long-term incubation, and it also induced the loss of lipid droplets and elongation of mature adipocytes by short-term incubation (Fig. 2). These observations suggest that TGF- $\beta 1$ inhibited the conversion of preadipocytes into adipocytes and induced de-differentiation of mature adipocytes. IFN $\alpha \beta$ had no effect on the adipocyte.

We then examined how the production of extracellular matrix may be regulated by determining the expression of pro$\alpha 2$ (I) collagen and TGF- $\beta 1$ mRNAs as well as the rate of synthesis of pro- $\alpha 2$ (I) collagen peptide. Figure $3 \mathrm{~A}$ shows the Northern blots for pro- $\alpha 2(\mathrm{I})$ collagen mRNA in the preadipocytes which had been exposed to retinoids, dexamethasone, TGF- $\beta 1$, IFN $\alpha \beta$ and IFN $\gamma$. As can be seen in Figs. 3A and 3B, retinoids enhanced the expression of pro- $\alpha 2$ (I) collagen mRNA in preadipocytes. The stimulating effects of retinoids on preadipocytes were not as obvious in differentiated mature adipocytes, as shown in Fig. 3D. Dexamethasone attenuated the expression (63\% of the control levels) in preadipocytes, where no apparent morphological alteration was observed after the 24 $h$ incubation. TGF- $\beta 1$ markedly increased the mRNA levels in preadipocytes (616\% of the control levels) and had the strongest effect among the agents examined (Fig. 3C). Both IFN $\alpha \beta$ and IFN $\gamma$ reduced markedly mRNA expression more than did dexa-methasone (31\% and $8 \%$ of the controls, respectively). Similar results were also obtained in the synthesis rate of pro$\alpha 2$ (I) collagen peptide in preadipocytes as shown in Fig. 4. Retinoids and TGF- $\beta 1$ enhanced while dexamethasone and IFNs decreased the synthesis rate of the peptide, which is consistent with the changes in the mRNA levels. Fig. 5A shows the Northern blots for TGF- $B 1$ mRNA in the preadipocytes. No significant effect was observed by treatmet with retinoids, dexamethasone, IFN $\alpha \beta$ or IFN $\gamma$, while TGF- $\beta 1$ enhanced predominantly its own expression (194\% of the control) as shown in Fig. 5C. These representative effects on type I procollagen and TGF- $\beta 1$ mRNA levels were reproducible in three repeated independent experiments.

We also examined the effects of the agents on the degradation of extracellular matrix (Fig. 6). Both retinoids and TGF-B1 


\section{Retinoids Modulate Collagen Production}

A

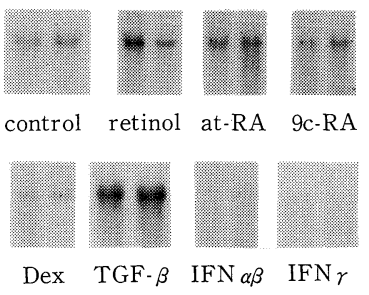

$\mathrm{B}$

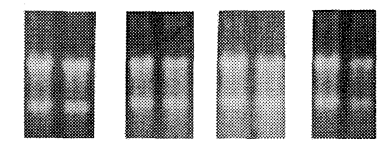

control retinol at-RA 9c-RA

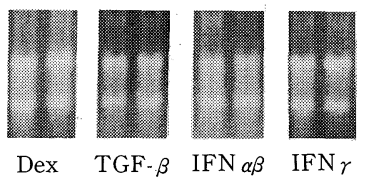

$\mathrm{C}$

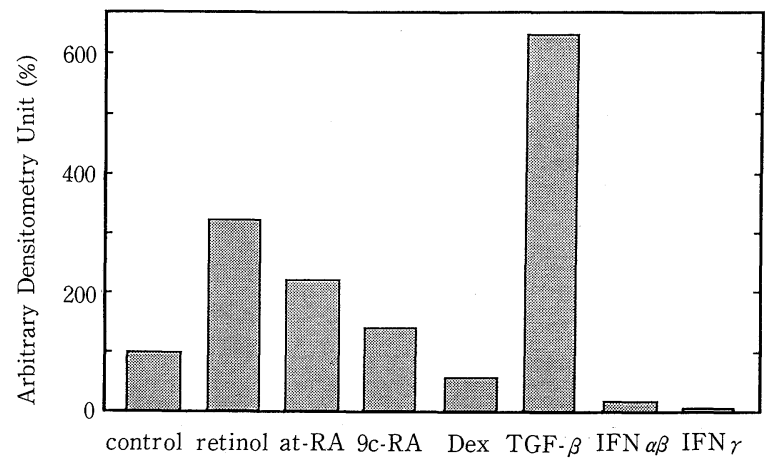

$\mathrm{D}$

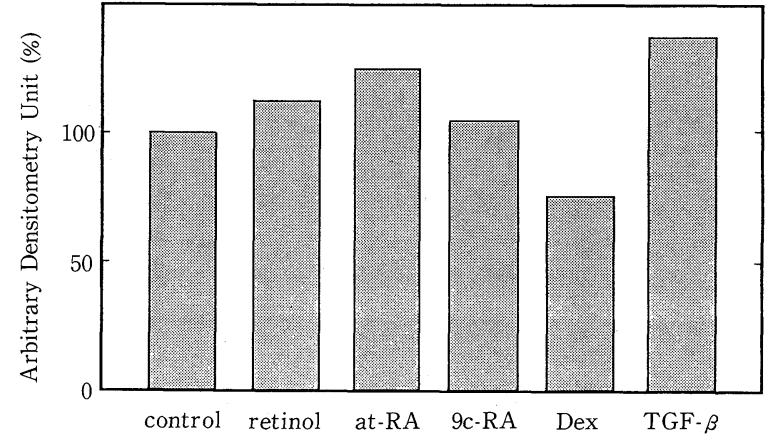

Fig. 3. Northern blot analysis for pro- $\alpha_{2}(\mathrm{I})$ collagen mRNA (Panel A). 3T3 $\mathrm{L} 1$ preadipocytes were incubated for $24 \mathrm{~h}$ with $1 \mu \mathrm{M}$ of retinoids or dexamethasone, $10 \mathrm{ng} / \mathrm{ml}$ of TGF- $\beta 1$ or $400 \mathrm{U} / \mathrm{ml}$ of IFN $\alpha \beta$ or IFN $\gamma$. Ten $\mu \mathrm{g}$ of total RNA was applied to each lane and stained with ethidium bromide (Panel B). Data from densitometric scans were standardized for the intensities of ethidium bromide staining and are given as the percentage of type I procollagen mRNA present in preadipocytes treated only with vehicle (Panel C). Similar experiments were performed in mature 3T3 L1 adipocytes which had been differentiated fully according to the differentiation protocol (Panel D). Representative values are shown in Panels C and D, which were reproducible in three independent experiments. Retinol: all-trans retinol, at-RA: all-trans retinoic acid, 9c-RA: 9-cis retinoic acid, Dex: dexamethasone, TGF- $\beta$ : transforming growth factor- $\beta$, IFN: interferon.

A

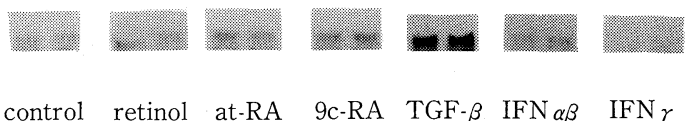

control retinol at-RA 9c-RA TGF- $\beta$ IFN $\alpha \beta$ IFN $\gamma$

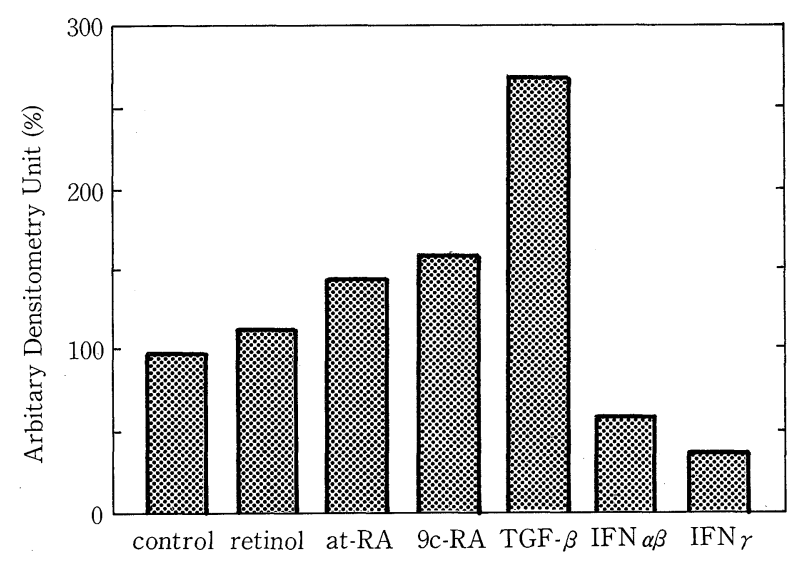

significantly reduced the activities of collagenase secreted by preadipocytes into their media. Dexamethasone also significantly inhibited collagenase activities in the medium. However, neither IFN $\alpha ß$ nor IFN $\gamma$ affected the activity.

\section{Discussion}

We reported previously that a retinoid analog can inhibit liver parenchymal damage and liver fibrosis induced by $\mathrm{CCl}_{4}$ (11). In contrast, in another model of liver fibrosis in which there was no liver parenchymal damage, we observed that the

Fig. 4. Autoradiogram of ${ }^{3} \mathrm{H}$-labelled pro- $\alpha_{2}(\mathrm{I})$ collagen peptide. $3 \mathrm{~T} 3 \mathrm{~L} 1$ preadipocytes were incubated for $24 \mathrm{~h}$ with $1 \mu \mathrm{M}$ of retinoids, $10 \mathrm{ng} / \mathrm{ml}$ of TGF$B 1$ or $400 \mathrm{U} / \mathrm{ml}$ of IFN $\alpha ß$ or IFN $\gamma$. Cells were then labelled with ${ }^{3} \mathrm{H}$-proline as described in "Materials and Methods". Cell lysates were electrophoresed on a polyacrylamide gel in the presence of sodium dodecyl sulfate (Panel A). Data from densitometric scans are given as the percentage of the density of the band in preadipocytes treated only with vehicle (Panel B). Retinol: all-trans retinol, at-RA: all-trans retinoic acid, 9c-RA: 9-cis retinoic acid, Dex: dexamethasone, TGF- $B$ : transforming growth factor- $\beta$, IFN: interferon. 


\section{NumAGUCHI et al}

A

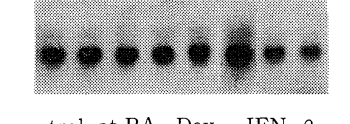

control at-RA Dex IFN $\alpha \beta$

retinol 9c-RA TGF- $\beta$ IFN $\gamma$

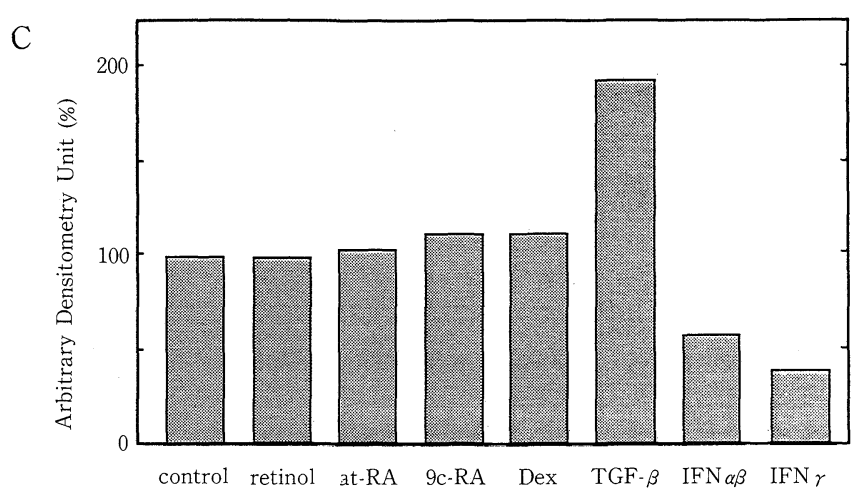

$\mathrm{B}$

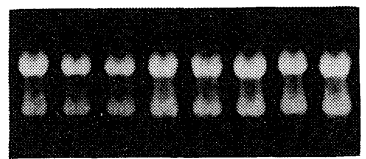

control at-RA Dex IFN $\alpha \beta$ retinol 9c-RA TGF- $\beta$ IFN $\gamma$

Fig. 5. Northern blot analysis of TGF- $B 1$ mRNA (Panel A). 3T3 L1 preadipocytes were incubated for $24 \mathrm{~h}$ with $1 \mu \mathrm{M}$ of retinoids or dexamethasone, $10 \mathrm{ng} / \mathrm{ml}$ of TGF- $B 1$ or $400 \mathrm{U} / \mathrm{ml}$ of IFN $\alpha \beta$ or IFN $\gamma$. Ten $\mu \mathrm{g}$ of total RNA was applied to each lane and stained with ethidium bromide (Panel B). Data from densitometric scans were standardized for the intensities of ethidium bromide staining and are given as the percentage of TGF- $\beta 1$ mRNA present in preadipocytes treated only with vehicle (Panel C). Representative values are shown in Panel $C$ which were reproducible in three independent experiments. Retinol: all-trans retinol, at-RA: all-trans retinoic acid, 9c-RA: 9-cis retinoic acid, Dex: dexamethasone, TGF- $B$ : transforming growth factor-B, IFN: interferon.

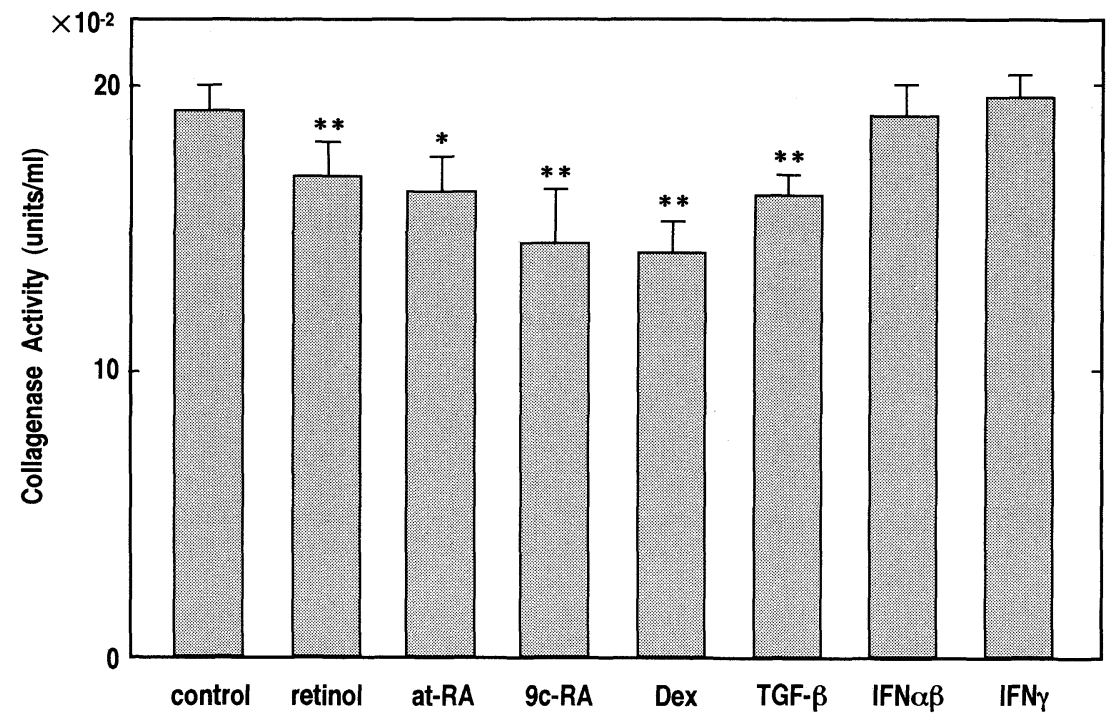

Fig. 6. Collagenase activities in the media of $3 \mathrm{~T} 3 \mathrm{~L} 1$ preadipocytes were measured as described in "Materials and Methods" after the incubations for $48 \mathrm{~h}$ with $1 \mu \mathrm{M}$ of a retinoid or dexamethasone, $10 \mathrm{ng} / \mathrm{ml}$ of TGF- $\beta 1$ or $400 \mathrm{U} / \mathrm{ml}$ of IFN $\alpha ß$ or IFN $\gamma$. Data are given as the percentage of the activities in control cells treated only with vehicle. Values for each treatment represent the mean $\pm \mathrm{SD}(\mathrm{n}=6)$. Retinol: all-trans retinol, at-RA: all-trans retinoic acid, 9c-RA: 9-cis retinoic acid, Dex: dexamethasone, TGF- $B$ : transforming growth factor- $\mathrm{B}$, IFN: interferon. $*$ : $\mathrm{P}<0.01, * *$ : $\mathrm{P}<0.001$.

retinoid analog enhanced fibrosis. The present study was designed to elucidate these conflicting effects of retinoids on fibrosis of the liver. To clarify the direct effect of retinoids on extracellular matrix-producing cells, we employed a cell cul- ture system based on 3T3 L1 preadipocytes which can be assumed to represent liver stellate cells. Our preliminary experiments confirmed that $3 \mathrm{~T} 3 \mathrm{~L} 1$ preadipocytes markedly reduced the expression of extracellular matrix proteins and the 
TGF- $\beta 1$ gene during the process of differentiation into mature adipocytes (data not shown), as reported previously by another group (13). These alterations of gene expressions are similar to those observed in stellate cells in which the expression of extracellular matrix protein and TGF- $\beta 1$ are enhanced in the myofibroblast-like cells while the mature quiescent stellate cells express those genes only faintly (17-19). We have also confirmed that a significant amount of retinoids exist in the lipid droplets of 3T3 L1 adipocytes (data not shown) similar to that in stellate cells, since the stellate cells are known to comprise a major storage site of retinoids in the liver (20).

The first important finding in the present study is that alltrans retinol stimulates cell growth beyond that caused by alltrans retinoic acid or 9-cis retinoic acid. Therefore, this growth promoting effect of retinol seems to be mediated, at least in part, through a mechanism other than the one which involves the nuclear receptors for retinoic acids. Recently reported was a new active metabolite of retinol, 14-hydroxy-4, 14-retro-retinol which does not bind to the nuclear receptors for retinoic acids and stimulates the proliferation of lymphocytes (21). Our preliminary experiments have shown that 14 -hydroxy-4, 14retro-retinol also stimulates the growth of 3T3 $\mathrm{L} 1$ preadipocytes (Okuno et al: unpublished observations). Since 14-hydroxy-4, 14-retro-retinol has also been detected in stellate cells of the fibrotic liver (22), this compound may be one of the most important candidates for such biological action. In contrast, all of the cytokines examined in the present study inhibited the growth of 3T3 L1 preadipocytes at the concentrations indicated. Although TGF- $\beta 1$ is known to stimulate the growth of some types of fibroblasts $(23,24)$, the ability of TGF- $\beta 1$ to inhibit growth in the present culture system was reproducible in several independent experiments. The reason for this inconsistency remains unclear. IFNs also attenuate the growth of 3T3 L1 preadipocytes, suggesting that the inhibitory effects of IFNs on the production of extracellular matrix are mediated not only through the reduction in the expression of extracellular matrix, as shown later, but also through attenuation of the cell growth of extracellular matrix-producing cells.

Next, we examined the effects of retinoids and cytokines on the differentiation of 3T3 L1 preadipocytes, since the ability of these cells to produce extracellular matrix are known to depend greatly upon the stage of differentiation (13). In both experiments in which we examined long-term and short-term effects, no retinoid altered the morphology of adipocytes. Although alltrans retinoic acid has been reported to inhibit the differentiation of 3T3 F442A adipocytes at concentrations higher than 10 $\mu \mathrm{M}$ (25), the relatively low concentration of retinoic acid examined here $(1 \mu \mathrm{M})$, could still influence the expression of extracellular matrix genes, and did not seem to influence the differentiation of $3 \mathrm{~T} 3 \mathrm{~L} 1$ adipocytes. In contrast, TGF- $B 1$ clearly suppressed the number of mature adipocytes in both experiments. These results suggest that the effect of TGF- $\beta 1$ on the production of the extracellular matrix may be mediated, in part, through regulation of the differentiation program of adipocytes. Thus, the effects of retinoids seem not to be mediated through modulation of the differentiation state of the cell.
The most important finding of the present study is that retinoids regulate the expression of type I procollagen mRNA as well as the synthesis rate of type I procollagen peptide, an extracellular matrix protein that is known to be increased predominantly in the fibrotic liver. The retinoids examined enhanced the expression of type I procollagen as well as its protein synthesis rate. No retinoic acid responsive element (RARE) has been found in the 5'-flanking region of the type I procollagen gene, therefore, enhancement of the gene expression by retinoids seems not to be mediated through the binding of nuclear receptors for retinoic acid to the gene, but may be mediated in part through secondary fibrogenic stimulation by cytokines. TGF- 31 , known to be a strong fibrogenic cytokine, was the strongest stimulant of type I procollagen expression in preadipocytes among the agents examined. Although retinoids did not enhance the expression of TGF-B1 mRNA as reported previously (26), retinoids were recently reported to activate latent TGF- $\beta$ and some retinoid actions are assumed to be mediated through the activation of this cytokine (26). To confirm this possibility, both the effects of retinoids on the activation of TGF- $\beta$ and the effect of the blockade of TGF- $\beta$ activity on retinoid action are being investigated in our laboratory. Interestingly, the fibrogenic effects of retinoids and TGF$B 1$ were found to be much weaker in differentiated adipocytes in which the basal level of the type I procollagen mRNA expression was much lower than that in undifferentiated preadipocytes. These observations suggest that not only do mature adipocytes produce collagen at a lower rate but also respond less to stimuli.

Another important finding of the present study is that IFNs suppress the expression of type I procollagen mRNA as well as the peptide synthesis rate. Recently, IFN $\alpha$ and IFNß have come into wide clinical use to treat chronic viral hepatitis and IFN therapy has been reported to reduce liver fibrosis in such patients (27). Our result suggests that IFN seems to act directly on extracellular matrix-producing cells while having an antiinflammatory effect due to its anti-viral action. IFN also reduced the expression of TGF- $\beta 1$ (Fig. 5) and this reduction seems to be one of the mechanisms by which the level of type I procollagen mRNA is attenuated. Rather, the apparent rate of decrease of collagen mRNA is more than would be expected due to the natural decay of the mRNA (Okuno et al, unpublished observation), suggesting that IFN may regulate the mRNA level by destabilizing specific transcripts and thus reducing the half-life of type I procollagen mRNA. For instance, dexamethasone is known to down-regulate the type I procollagen mRNA level, as shown in Fig. 3, by decreasing the half-life of the transcript (28). It should be noted that the type I procollagen mRNA level is suppressed more by IFN-treatment than by treatment with dexamethasone. However, the mechanism of such down-regulation remains to be clarified.

Retinoids, as well as TGF-B1, decrease the activities of secreted collagenase in the media. Since the deposition of extracellular matrix in the tissue is known to be the sum of the production and the degradation, regulation of the rate of collagen fibril degradation also seems to be an important factor in 
modulating the fibrosis. Taken together, both retinoids and TGF- $\beta 1$ are thought to enhance the deposition of collagen in tissues both by increasing the production and by decreasing the degradation of the fibers.

In summary, retinoids are found to stimulate the production and deposition of extracellular matrix by mesenchymal cells. This seems consistent with the finding that a retinoid analog stimulates liver fibrosis in rats treated with porcine serum. In this model, the retinoid may act directly on stellate cells to enhance the production of extracellular matrix in the liver, since porcine serum induced no inflammatory reaction in the liver. In contrast, retinoids inhibited liver fibrosis in the model of liver cirrhosis caused by $\mathrm{CCl}_{4}$. In this model, the retinoid also decreased the serum activities of alanine aminotransaminase (ALT) and asparatate aminotransferase (AST) as well as the histological degree of liver parenchymal damage. A cytoprotective effect of the retinoid may somehow reduce the inflammation in the liver and thereby inhibit fibrosis. Thus, retinoids seem to have two opposing effects on liver fibrosis in vivo: a fibrogenic effect on mesenchymal cells and a cytoprotective effect on parenchymal cells which can inhibit fibrosis.

At present, we do not fully understand how retinoids act on extracellular matrix-producing cells or which retinoid metabolite is most fibrogenic. It will also be necessary to elucidate the effects of retinoid antagonists, that block the transcriptional activation of retinoid-responsive genes, on liver fibrosis since it would seem to be reasonable to also use, in the future, retinoid antagonists to treat liver fibrosis.

Acknowledgements: We express our appreciation to Drs. Yasuhiro Yamada (Gifu University) and Ieharu Hishinuma (Eisai Co.) for their helpful discussions.

This work was supported in part by a Grant-in-aid for scientific research from the Ministry of Education, Science and Culture of Japan; a Grant-in-aid for cancer research from the Ministry of Health and Welfare of Japan; and a Grant from the Princess Takamatsu Cancer Research Fund.

\section{References}

1) Gressner AM. Liver fibrosis: Perspective in pathobiochemical research and clinical outlook. Eur J Clin Chem Clin Biochem 29: 293, 1991.

2) Friedman SL. The cellular basis of hepatic fibrosis. N Engl J Med 328: 1828,1993

3) Ignotz RA, Massague J. Transforming growth factor-beta stimulates the expression of fibronectin and collagen and their incorporation into the extracellular matrix. J Biol Chem 261: 4337, 1986.

4) Raghow R, Postlethwaite AE, Keski-Oja J, Moses HL, Kang AH. Transforming growth factor beta increases steady-state levels of type I procollagen and fibronectin mRNAs posttranscriptionally in culture human dermal fibroblasts. J Clin Invest 79: 1285, 1987.

5) Penttinen RP, Kobayashi $S$, Bornstein $P$. Transforming growth factor beta increases mRNA for matrix proteins both in the presence and in the absence of changes in mRNA stability. Proc Natl Acad Sci USA 85: 1105, 1988.

6) Blomhoff R, Wake K. Perisinusoidal stellate cells of the liver: important roles in retinol metabolism and fibrosis. FASEB J 5: 271, 1991.
7) David BH, Pratt BM, Madri JA. Retinol and extracellular matrix modulation hepatic Ito cell collagen phenotype and cellular retinol binding protein levels. J Biol Chem 262: 10280, 1987.

8) Vasios GW, Gold JD, Petkovich M, Chambon P, Gudas LJ. A retinoic acid-responsive element is present in the 5' flanking region of the laminin B1 gene. Proc Natl Acad Sci USA 86: 9099, 1989.

9) Wang SY, Gudas LJ. Isolation of cDNA clones specific for collagen IV and laminin from mouse teratocarcinoma cells. Proc Natl Acad Sci USA 80: 5880,1983

10) Geubel AP, De Galocsy C, Alves N, Rahier J, Dive C. Liver damage caused by therapeutic vitamin A administration: estimate of dose-related toxicity in 41 cases. Gastroenterology 100: 1701, 1991.

11) Okuno M, Muto $Y$, Moriwaki $H$, Kato M, Noma A, Tagaya O, Nozaki $Y$, Suzuki Y. Inhibitory effect of acyclic retinoid (polyprenoic acid) on hepatic fibrosis in $\mathrm{CCl}_{4}$-treated rats. Gastroenterol Jpn 25: 223, 1990.

12) Okuno M, Muto $Y$, Kato M, Ninomiya M, Moriwaki H, Noma A, Tagaya $\mathrm{O}$, Nozaki Y, Suzuki Y. Inhibitory effect of acyclic retinoid (polyprenoic acid) on the secretion of $\alpha$-fetoprotein in $\mathrm{CCl}_{4}$-treated rats. J Nutr Sci Vitaminol 36: 437, 1990

13) Weiner FR, Shah A, Smith PJ, Rubin CS. Regulation of collagen gene expression in 3T3-L1 cells. Effects of adipocyte differentiation and tumor necrosis factor $\alpha$. Biochemistry 28: 4094, 1989 .

14) Rubin CS, Hirsch A, Fung C, Rosen OM. Development of hormone receptors and hormonal responsiveness in vitro. J Biol Chem 253: 7570, 1978.

15) Mosmann T. Rapid colorimetric assay for cellular growth and cytotoxicity assays. J Immunol Methods 65: 55, 1983.

16) Chomczynski P, Sacchi N. Single-step method of RNA isolation by acid guanidinium thiocyanate-phenol-chloroform extraction. Anal Biochem 162: 156, 1987.

17) Friedman SL, Roll FJ, Boyles J, Arenson DM, Bissel DM. Maintenance of differentiated phenotype of cultured rat hepatic lipocytes by basement membrane matrix. J Biol Chem 264: 10756, 1989.

18) Geerts A, Vrijsen R, Rauterberg J, Burt A. In vitro differentiation of fatstoring cells parallels marked increase of collagen synthesis and secretion. J Hepatol 9: 59, 1989

19) Weiner FR, Giambrone MA, Czaja MJ, Shah A, Annoni G, Takahashi S, Eghbali M, Zern MA. Ito-cell gene expression and collagen regulation. Hepatology 11: 111, 1990.

20) Wake K, Motomatsu K, Senoo H. Stellate cells storing retinol in the liver of adult lamprey, Lampetra japonica. Cell Tissue Res 249: 289, 1987.

21) Buck J, Derguini F, Levi E, Nakanishi K, Hammerling U. Intracellular signaling by 14-hydroxy-4,14-retro-retinol. Science 254: 1654, 1991.

22) Friedman SL, Yamasaki G, Wong J, Buck J. 14-Hydroxy-4,14-retroretinol - a novel metabolite of retinol produced by activated rat lipocytes in vivo and in culture. Hepatology 16: 143A, 1992 (Abstract).

23) Robert AB, Sporn MB. The Transforming Growth Factor-ßs. in: Peptide Growth Factors and Their Receptors I, Sporn MB, Robert AB, Eds. Springer-Verlag, Berlin, 1990, p. 419.

24) Massague J. The transforming growth factor- $B$ family. Ann Rev Cell Biol 6: 597,1990 .

25) Wilkinson WO, Min HY, Claffey KP, Satterberg BL, Spiegelman BM. Control of the adipsin gene in adipocyte differentiation. J Biol Chem 265: 477, 1990.

26) Kojima S, Rifkin DB. Mechanism of retinoid-induced activation of latent transforming growth factor- $\beta$ in bovine endothelial cells. J Cell Physiol 155: 323, 1993.

27) Castilla A, Prieto J, Faust N. Transforming growth factor $B 1$ and $\alpha$ in chronic liver disease: effects of interferon alpha therapy. $\mathrm{N}$ Engl J Med 324: $933,1991$.

28) Raghow R, Gossage D, Kang AH. Pretranslational regulation of type I collagen, fibronectin, and a 50-kilodalton noncollagenous extracellular protein by dexamethasone in rat fibroblasts. J Biol Chem 261: 4677, 1986. 